\title{
Diarinho: a ideosfera do sensacionalismo
}

\section{Diarinho: the ideosphere of sensationalism}

Roberto José Ramos

Pós-doutor em Ciências da Comunicação pela Unisinos, Doutor em Educação pela PUCRS, professor do PPGCom e da Graduação da Faculdade de Comunicação Social da PUCRS.

$<$ rr@pucrs.br>

\section{RESUMO}

Sem meias palavras, o jornal Diarinho, que circula no Vale do Itajaí, em Santa Catarina, assume uma condição: é sensacionalista. Parece buscar a contramão dos denominados grandes jornais. A designação, Diarinho, no diminutivo, parece estar investida do sentido de "empatia", como identificação (Maffesoli, 1988). Pode ser o signo de afetividade e de intimidade, estabelecida entre o jornal e os seus sujeitos leitores. A singularidade da linguagem do Diarinho foi abordada neste artigo, através da Semiologia, de Roland Barthes. O sensacionalismo parece apresentar algumas particularidades. É explícito, pronuncia-se pela coloquialidade da linguagem e pelo tipo de informação, que utiliza. Sendo assim, estabelece diálogos com diferentes poderes, próprios das mídias.

\begin{abstract}
Straight to the point, the newspaper Diarinho, from Vale do Itajaí, in Santa Catarina, assumes a condition: It's muckraker. It looks like to want to walk against the called majors newspapers. The designation, Diarinho (little daily), in the diminutive, seems to be endowed with the sense of "empathy", as identification (Maffesoli, 1988). It can be the sign of affection and intimacy, established between the newspaper and its readers. The uniqueness of Diarinho language was discussed in this paper, by the Roland Barthes Semiology. The sensationalism seems to present some particularities. It is explicit, pronounced by the colloquial language and the type of information, which uses. In this way, establishing dialogues with the different powers, that are inside the media.
\end{abstract}

\section{Introdução}

Nas ruas das cidades do Vale do Itajaí, assistimos à venda do Diarinho desde as primeiras horas da manhã. É um ritual urbano e cotidiano de um jornal, que parece não denegar a sua postura sensacionalista, assumindo-a em cada signo impresso. Dispõe, ainda, de uma versão on-line.

O Vale do Itajaí é o perfil mais rico do território de Santa Catarina, expressando os melhores traços do sentido de qualidade de vida. Possui dez municípios, que sintetizam 800 mil habitantes, aproximadamente, $20 \%$ da população catarinense. 
Barthes (1988) observa que o resgate etimológico possui relevância.É uma forma de compreender a hegemonia do significante em relação ao significado, particularizando uma prática, própria e importante do olhar do Estruturalismo.

No rastro de tal sentido, Althusser (1992, p. 193) notabiliza a importância do Nominalismo, como um significante, que afirma a materialidade:

[...] Marx iria me ensinar que o nominalismo é o caminho real, para o materialismo, a bem da verdade, é uma via, que só desemboca em si mesma, e não conheço forma mais profunda do materialismo, além do nominalismo [...].

Cabe praticarmos os resgates etimológicos dos nomes próprios do objeto deste ensaio. São, basicamente, dois: Itajaí e Diário do Litoral, o Diarinho. O rio nomeou a cidade. Os índios o denominaram Itajaí, que já experimentou uma pluralidade de grafias: "Táahy”, “Tajay", "Tajahug” e "Itajaí”, de acordo com Glück (2000, p. 7).

A questão nominalística, em termos de grafia e semântica, vem sendo discutida há mais de um século. "Só após 1799, o vocábulo se fixou na forma atual, Itajaí. Sua interpretação fica entre 'Rio das Pedras', ou 'Rio dos Taiás'”, como informa Glück (2000, p. 7).

Já o Diário do Litoral, mais conhecido como Diarinho, apresenta uma particularidade. Vincula o termo, Diário, significando jornal, a uma característica do espaço geográfico: o litoral. A designação, Diarinho, no diminutivo, parece estar investida do sentido de Empatia, como identificação, conforme Maffesoli (1988). Pode ser o signo de afetividade e de intimidade, estabelecida entre o jornal e os seus sujeitos leitores.

A cidade de Itajaí é a segunda mais importante da região. Possui, aproximadamente, 160 mil habitantes. Desfruta do mais significativo porto pesqueiro do país e de uma diversidade cultural e econômica admiráveis, conforme Glück (2000, p. 7).

Em 12 de janeiro de 1979, o advogado Dalmo Vieira, já falecido, começou a materializar um sonho. Fundou o Diário do Litoral, em Itajaí, hoje mais conhecido como Diarinho. As folhas de papel almaço, associadas a uma máquina de escrever, Lettera 22, colocaram-no nas ruas. Eram os primeiros passos de um ideal de Vieira - um jornal popular e independente.

O cotidiano parece ser o palco preferido pelo Diarinho. É semiologizado, sobretudo, por algumas editorias essenciais, que governam, em geral, as suas manchetes. Cabe destacarmos à de Polícia, à de Esporte e à de Geral. Além delas, 
a seção Transe Tudo se dedica aos anúncios classificados, que se distribuem, geralmente, em 12 páginas. Parecem ter a disposição para vender quase tudo.

O Diarinho já se tornou, também, objeto de estudo acadêmico. Foi abordado pela dissertação de Sommer (2003), no Mestrado de Comunicação Social, da Pontifícia Universidade Católica do Rio Grande do Sul (PUCRS), na Faculdade de Comunicação Social (FAMECOS). Ao estudá-lo, Sommer (2003, p. 120) produziu algumas evidências importantes, através do viés do Jornalismo. Considerou-o, como sensacionalista.

Conta, em média, com 48 páginas e uma tiragem em torno de nove mil exemplares. Em 2010, foi lançado o novo site do jornal na internet, o Diarinho Online. Possui sucursais em Itajaí, Balneário Camboriú, Navegantes e Florianópolis.

Este artigo, em suas limitações e precariedades, tecerá algumas reflexões sobre o sensacionalismo, agenciado pelo Diarinho. Usaremos, para tanto, a Semiologia, de Roland Barthes, em suas possibilidades transdisciplinares, para o estudo da produção de sentido.

\section{Semiologia barthesiana}

A Semiologia começou a ganhar notoriedade na França a partir da década de 1950. Trazia, na época, uma influência notória. Estava impregnada pelos signos do pensamento de Saussure, na perspectiva de uma abordagem estruturalista, de teor funcionalista. Barthes não fugiu a tal tendência. Tornouse um dos discípulos de Saussure. Deu os seus primeiros passos semiológicos dentro da régua e do compasso do Estruturalismo, de abordagem funcionalista. Todavia, gradativamente, foi reciclando a sua concepção sobre o papel dos signos.

O semiólogo possui duas tarefas básicas, observa Barthes (1996). Deve se preocupar com a formulação de conceitos e se ocupar, com o desenvolvimento de pesquisa. É a possibilidade de juntar a teoria e a prática, em uma síntese do saber-fazer, com um sentido histórico.

O discurso barthesiano, nesse sentido, parece ter correspondido à prática. Barthes deixou, em sua completude e em sua incompletude, um legado teórico e analítico, com as digitais de uma singularidade. Evidenciou a essencialidade da Conotação, na compreensão da realidade dos signos. Como crítico e ensaísta, na pluralidade das suas obras, ela possui um sentido invariante. Foi obsessivo na produção conceitual, por vezes, com profundidade; por outras, com superficialidade. Valorizou a Linguagem como um evento decisivo na produção cultural. A sua produção de pesquisa, ao longo de quase três décadas, 
apresentou uma variedade temática. A Mídia, todavia, foi uma invariância. Ela teve importância, já a partir da década de 1950, com a obra Mitologias (1993), quando não era tão importante, quanto na contemporaneidade.

Talvez, uma interrogação possa ser pertinente: quando a Semiologia, de Barthes, se torna, essencialmente, barthesiana? A resposta exige alguns resgates de algumas obras, para que possamos compreender a sua ruptura epistemológica, como um evento superdeterminado.

Barthes (1996) lança três teses, em um primeiro olhar, sobre a Semiologia. Ele assinala que a sua Semiologia é Negativa e Ativa, bem como reitera o papel do semiólogo. Na Negativa, há uma negação. O signo não é fixo, não é absoluto, nem positivo. É, ao contrário, relativo - uma produção social e cultural.

Na Ativa, ocorre a pormenorização do objeto de estudo. São os textos do Imaginário - ilusão, fantasia, conforme Barthes (s. d.). Ele os especifica, como as narrativas, imagens, retratos, expressões e idioleto, ou seja, o repertório de manifestações linguageiras, que habitam o cotidiano.

A seguir, há a fixação do papel do semiólogo. Ele não é um detetive, que investiga e pretende desvendar os enigmas. Não é, também, um pescador da verdade absoluta. Barthes (1996, p. 40) desenha o seu perfil: "O semiólogo seria, em suma, um artista (essa palavra não é, aqui, nem gloriosa, nem desdenhosa, refere-se somente a uma tipologia): ele joga com os signos, como um logro consciente, cuja fascinação saboreia, quer fazer saborear e compreender".

Na perspectiva do discurso, a Semiologia Negativa, Ativa e o papel do semiólogo parecem compor três teses. A Semiologia Negativa assume um sentido óbvio. Possui a dimensão imaginária de uma tese, através de uma relação sintagmática. Existe, porém, a perspectiva de ir além do óbvio, em seu continente imaginário. É importante o resgate do obtuso, em sua densidade simbólica, em sua relação paradigmática.

O conceito de Cultura, como Intertexto, segundo Barthes (s.d.) vem à tona. Caracteriza os textos, que influenciam a produção textual. Emergem as relações ambivalentes dos papéis de pais e de discípulos. É a relação entre o criador e a criatura, através da imagem e da semelhança.

O pai teórico e metodológico de Barthes foi Saussure. O óbvio da Semiologia Negativa, que parece uma tese, tem o seu obtuso. É a obra de Saussure, como Intertexto. Lá, se encontra a dimensão linguística do signo, como perfil positivo, fixo e absoluto.

A Semiologia Negativa deixa de ser vislumbrada, imaginariamente, como uma tese. Passa a ser vista, como uma Antítese à Semiologia de Saussure, em sua determinação positivista. O mesmo ocorre com a Semiologia Ativa. Perde o 
seu sentido imaginário e óbvio de tese. Ganha um sentido simbólico e implícito de Antítese, também, à compreensão semiológica de Saussure.

A Semiologia Negativa e Ativa compõem, em suas relações, uma Antítese. O papel do semiólogo, em consequência, é uma Síntese. Está sedimentado o triunvirato da Dialética. A Tese é saussuriana, a Antítese e a Síntese, barthesianas.

Tal ritual, que se parece com o ato do adolescer contra o pai, como símbolo da Ordem, traz uma alusão. A rebeldia de Barthes ao pai, teórico e metodológico, Saussure, conota mais do que uma mera bravata entre criatura e criador. É uma ruptura epistemológica.

A Semiologia barthesiana se singulariza. Adquire a sua própria fisionomia. Não deixa de ser estruturalista, porém se recicla. Apresenta uma nova abordagem sobre o signo, através de uma perspectiva dialética, que procura abraçar o social e o subjetivo.

O signo é visto em sua dupla face. Apresenta uma determinação da Língua, mas, também, da Fala. Recebe uma leitura linguística, e, ao mesmo tempo, translinguística, que amplia a perspectiva. Tem uma singularidade polissêmica, marcada e demarcada pela historicidade.

Ao considerar a importância da Fala, há a consideração de alguns aspectos básicos. Entram, em pauta, as questões culturais e ideológicas, que reivindicam uma prática interdisciplinar e transdisciplinar, pouco exploradas e explicitadas pelo semiólogo.

A Semiologia teve, em Barthes, uma tonalidade específica. Ganhou uma nova denominação batismal. Foi ungida como Semiologia, estabelecida com conceitos:

\footnotetext{
A Semiologia é uma Ciência das formas, visto que estuda as significações, independentemente do seu conteúdo (...) Recordo, portanto, que toda a Semiologia postula uma relação entre dois termos, um Significante e um Significado (Barthes, 1993, p. 134).
}

A iluminação das formas, que o homem usa, para representar as suas realidades, é a geografia, onde se move a Semiologia. Ela caminha no território do quotidiano, desarrumando a arrumação dos álibis dos Signos, para revelar a clarividência do Poder.

A epistemologia barthesiana tem sido instabilizada por alguns prefixos "neo", "pós". Tais questionamentos, justificados por uma adolescência teórica, naufragam na tábua-rasa da superficialidade. Afogam-se nas gotas de uma estereotipia, que consagra um perfil pouco alinhado com a cientificidade. 
Independente da prefixação, o endereço é o mesmo. Todos deságuam no mesmo mar. Buscam as águas da Matriz do Estruturalismo. É a invariância do paradigma do semiólogo francês, que possui, na forma, a invariante, como pressuposto norteador.

Nos Signos, está o Poder, embrenhado na linguagem, no escaninho da língua, como um parasita atemporal. Não cessa de interpelar, colecionando súditos, materializando a imperatividade de sua vontade. Barthes (1996, p. 1012) o enquadra conceitualmente:

[...] O Poder é parasita de um organismo transsocial, ligado à história inteira do homem e não somente a sua história política, histórica. Esse objeto, em que se inscreve o Poder, desde toda a eternidade, é: a Linguagem e para ser preciso, sua expressão obrigatória: a Língua. [...] O Poder é a libido "dominandi", aí, está emboscado em todo o discurso.

O semiólogo concede tentáculos interdisciplinares à Semiologia. Inventaria a sua afinidade com a Psicanálise, criada por Freud, que desestabilizou a noção idealista de sujeito. Revelou que o homem não é determinado pelo seu consciente, porém pelo seu Inconsciente.

O conceito de Libido tem se prestado a diferentes interpretações. Alguns o emparedam na sinonímia do prazer sexual em uma postura redutora e simplificante. Outros conseguem caracterizá-lo com mais amplitude, traduzindo-o como energia prazerosa.

A primeira perspectiva não descobriu, ainda, a pluralidade da atuação da Libido. Não saiu da fase edipiana, onde a sexualidade é uma planície, que consegue tapar, com sua finitude, a silhueta infinita do horizonte. A outra perspectiva estabelece uma leitura mais pertinente com os textos freudianos. Ainda que a sexualidade seja o instinto mais forte no ser humano, há a evidência de outras formas prazerosas. A Libido é a energia prazerosa, própria do Instinto de Eros, que dá, ao homem, motivações para viver. Possui várias manifestações, uma das quais é a sexual.

O Poder, configurado por Barthes, é a energia prazerosa dominante. Significa a legitimação da vida, o seu pré-requisito indissociável. Independe de modelos e conjunturas sociais e especificidades temporais, mesmo que deles dependa a particularização de sua onipresença. Pronunciar-se pela Linguagem, através do seu código invariante: a Língua.

Nos aclives e declives do solo da Semiologia, Barthes teve engenho. Construiu um conceito de Poder, exemplar pelo seu sentido interdisciplinar, mas balizado pelo compromisso com a precisão. Adicionou, ao Estruturalismo, 
uma estrada vicinal com a dialética. Elucidou que a Invariância não é estática, mas toda a condição de movimento, agenciado pela supremacia do essencial em relação ao secundário.

Barthes (1979) salienta que a Semiologia e a Sociologia possuem objetos diferentes de estudo. A primeira se preocupa com a representação do real, através do imaginário; a segunda está fixada na concretude do real, pela pronúncia dos papéis e das práticas.

Tal distinção é pertinente, porém sustenta, na sua implicitude, o elo interdisciplinar entre a Semiologia e a Sociologia. Ambas convergem, em suas singularidades, para a dimensão social, inscrita nos escaninhos da linguagem e das práticas, que se encontram interrelacionadas.

Sem ser filósofo, Barthes não dá luminosidade às práticas epistemológicas. Ele sintetiza as relações linguísticas e translinguísticas, conservando uma postura estruturalista, em diálogo com a Dialética. Desestabiliza o sentido absolutizante das funções, em nome de um sentido relativizante da produção semiológica.

Os traços da Semiologia barthesiana se delineiam, com clareza (Barthes, 1996). Ele lança duas teses: a Semiologia Negativa e a Ativa. Delas, extrai uma síntese: a categorização de Semiologia. Na Negativa, anota o seu caráter apofático. Nega os caracteres positivos, fixos, a-históricos do signo. Desfaz a Semiologia, como metalinguagem, qualificando a sua relação ancilar com outras disciplinas.

Na Ativa, sustenta que ela não é semiofísis, nem semioclastia. Ela é semiotropia, porquanto trata e imita o signo, buscando compreendê-lo. O seu objeto são os textos do Imaginário. Diante disso, Barthes (1996, p. 41) propõe a sua concepção, como "o curso de operações ao longo do qual é possível quiçá almejado - usar o signo, como um véu pintado, ou, ainda, uma ficção".

Barthes trabalha a tríade da Dialética - Tese, Antítese e Síntese. Fixa o movimento de negações e afirmações, que desaguam em uma dedução sobre a historicidade do signo, que impõe a tarefa de compreensão à Semiologia. As negações simbolizam a ruptura com o Estruturalismo funcionalista, de Saussure. As afirmações contextualizam uma nova abordagem da Semiologia: relativizadora, com os pés na realidade histórico-social. Sintonizam com os princípios da Dialética Histórico-Estrutural - DHE.

O semiólogo Barthes apresenta uma resposta quase pronta, para a pergunta: o que é a Semiologia? "É uma aventura, quer dizer, aquilo que me acontece (o que me vem do Significante)". Ele a divide em três momentos: 
1. O primeiro momento foi de admiração. A linguagem, ou para ser mais preciso, o discurso, foi o objeto constante do meu trabalho desde o meu primeiro livro, O Grau Zero da Escrita (...) 2. O segundo momento foi o da Ciência, ou, pelo menos, da cientificidade. (...) Para mim, o que domina este período do meu trabalho, creio eu, é menos o projeto que fundara a Semiologia, como Ciência, que o prazer de exercer uma Sistemática (...) 3. O terceiro momento é, com efeito, o do Texto. Teciam-se discursos à minha volta, que deslocavam preconceitos, inquietavam evidências, propunham novos conceitos [...] (Barthes, 1987, p.12).

A Semiologia oferecerá contribuições ao nosso estudo. Normatizará os procedimentos de aplicação das categorias de Barthes e de Morin, nas suas respectivas correspondências já propostas, em sua perspectiva transdisciplinar. Será a técnica metodológica, isto é, operacionalizará, com particularidade, a Complexidade. Barthes (1997, p. 106) caracteriza o objetivo essencial da Pesquisa Semiológica:

[...] Não podemos prever o ritmo de mudança dos sistemas, visto que o objetivo, talvez, essencial da Pesquisa Semiológica (isto é, aquilo que será encontrado em último lugar) é, precisamente, descobrir o tempo próprio do sistema, a história das formas.

Barthes (1971) estabelece o perfil de sua Semiologia. Concede-lhe alguns traços essenciais. Valoriza a relevância do Significante e da Conotação. Tece pressupostos teóricos, como o Fait Divers - a informação sensacionalista decisivo para uma leitura consequente do Sensacionalismo.

\section{Leitura semiológica do Diarinho}

A edição do Diarinho On-line, de 30 de outubro de 2014, trouxe, entre outras chamadas de capa, a seguinte: "Bandidos entram em creche armados e roubam carro em Itajaí". Parece-nos um fragmento semiológico, representativo da tipologia informativa do jornal. Será o nosso exemplo de caso. Eis a sua transcrição:

A audácia da bandidagem vai longe. Ontem, às $17 \mathrm{~h} 50$, dois carinhas entraram com um revólver na creche Municipal Euclides Ciríaco Meirinho, na rua das Azaléias, no bairro Cidade Nova, em Itajaí. Eles queriam a chave de um veículo Golf estacionado na frente da unidade escolar. Quando conseguiram, simandaram com o possante. A polícia Militar foi chamada e com as informações do rastreador conseguiu 
localizar o carango. O Golf tava coberto por um colcha na garagem de uma casa na rua Maria Nunes da Silva, no São Viça. No local, os milicos localizaram a muié A. A. dos S. A., 33 anos, e o carinha V. A. S., 23. Ambos foram presos e conduzidos pra central de Plantão Policial (Diarinho, 2014).

O título ganha interpelação, com duas opções léxicas. São os casos da expressão "Bandidagem" e do termo "Creche". Ambos estão investidos de uma oposição básica, que se torna indissociável. Materializa-se uma Antítese, onde os opostos se tornam inseparáveis.

A "Bandidagem" compromete-se em interpelar, por intermédio da produção de sentido, inscrita no signo de valorização do sensacional. Configurase, como um Estereótipo - a imagem fixa, a palavra repetida, conforme Barthes (1988). Possui uma performance de rótulo classificatório, de caráter imanente.

Os termos, "carinhas" e "carinha", no diminutivo, oferecem uma aproximação temporal e espacial. Sintetizam-se pela articulação do Estereótipo. A gíria viabiliza-se, também, pela escolha da expressão, "um pá de dor de cabeça”. Pronuncia-se, por um sentido condensado e sintético, próprio da Metonímia, como Figura de Linguagem.

As gírias, em suas expressões orais, ganham visibilidade. Pluralizam-se em "carango", "milicos", "muié" e "simandaram". Configuram a materialidade do coloquial, que se torna discurso escrito, bem ao gosto do senso comum, em seu apego de fala cotidiana.

Barthes (1988) refere dois tipos de Linguagem. A Linguagem Objeto se caracteriza por traduzir o vivido, o experimentado. Pertence a algo. A Linguagem Imagem é diferente. Mantém o distanciamento entre o sujeito e o objeto. Não tem pertencimento a algo. É sobre algo.

A hegemonia de gírias e de expressões orais traz uma evidência. Existe um vínculo entre os recursos verbais e a experiência vivencial. Não há diferenças entre a fala e a escrita. Assim sendo, se particulariza a presença da Linguagem Objeto.

As Antíteses dramáticas parecem mover a produção de sentido. Representam o mal, o delito, e o bem, através da Creche e da Polícia. Tal duelo parece ter encontrado o seu desenlace. A insígnia policial, como o bem, vence. É triunfo da vida. Desenha-se o final feliz, para o discurso da repressão do Estado.

Não há relação entre os ladrões e o social. São realidades, esquizofrenicamente, sem vértices e sem dialogicidade. Estão dissociadas. Não possuem vínculos. Encontram-se separados. São extremos maniqueístas. Possuem endereços diferentes. 
Ao longo do século XX, alguns teóricos dimensionaram a importância do Fait Divers. Foram os casos, especialmente, de Morin (1984) e Baudrillard (1995). Ambos o visitaram e o revisitaram, com um mesmo endereço e interesse: a questão conceitual.

Morin (1984, p. 114-115) vê, no Fait Divers, "os acontecimentos contingentes, que só se justificam por seu valor emocional. Ele salienta a sua composição trágica, na qual se desenvolve, pelo Sensacionalismo, "a lógica irreparável da Fatalidade".

Baudrillard (1995, p. 24) parece ter uma maior ousadia teórica, ainda que não disponha de um melhor aprofundamento. Ele sustenta que a"universalidade do Fait Divers" é uma das características da sociedade de consumo, através da "Comunicação de massa". Ainda, acrescenta: "Toda a informação política, histórica e cultural é acolhida sob a mesma forma, simultaneamente anódina e miraculosa do fait divers".

A expressão francesa Fait Divers, traduzida como casos do dia, designa, em geral, a informação sensacionalista. Barthes (1971, p. 263) a caracterizou pelo seu sentido monstruoso, sendo "análoga a todos os fatos excepcionais ou insignificantes, em resumo anônimos".

Através da angulação estrutural, o semiólogo propôs dois tipos básicos: Causalidade e a Coincidência. Ambos, em suas respectivas pronúncias, formalizam a noção de conflito, fixada em sua notificação presenteísta, de extração narcísica, que interpela pela exploração da emoção.

O de Causalidade apresenta duas manifestações (Barthes, 1971): a) Causa Perturbada - há o desconhecimento causal, ou, ainda, quando uma causa provoca um grande efeito: b) Causa Esperada - quando a causa é normal, a ênfase recai nos Personagens Dramáticos - mãe, criança e idoso.

O de Coincidência possui, também, dois subtipos (Barthes, 1971, p. 265): a) Repetição - o igual, que se reproduz, com diferença, conforme Lacan (1996); b) Antítese - duas perspectivas diferentes, antagônicas, são fundidas, como se fossem uma única realidade. Pode se manifestar, através do drama e da tragédia.

As crianças da creche são Personagens Dramáticos. Poderiam caracterizar a perspectiva de um Fait Divers de Causalidade, de Causa Normal, em sua simbologia cultural, porém a realidade parece ser bem outra. Encontram-se envoltas nas relações com o assalto, como signo da violência.

A cena se move e é movida pela presença da Antítese - assalto-crianças. Existe o agenciamento da produção de sentido ao longo do curso do discurso. Singulariza uma tipologia informativa. Consolida-se, em especial, o Fait Divers de Coincidência. 
Barthes (1971) observa que a noção de Coincidência conduz à ideia de Fatalidade, como um Deus-ex-machina. É o Sujeito Absoluto, como explicação metafísica, para a história. A banalização dos crimes, através da Repetição, ainda que tenham causas, estas se esterilizam historicamente. Parecem se sintetizarem no Acaso. A Antítese trágica se particulariza, por intermédio do Cúmulo, como a situação de má-sorte.

Lacan (1996, p. 56) resgata a importância de Tiquê - a deusa grega da fortuna. Ela equivaleà noçãolatina de Destino. Encontra-sevinculadaà Repetição. Com isso, a Fatalidade, como Sujeito Absoluto, neste Fait Divers de Coincidência, ganha singularidade. É Tiquê, como Deus-ex-machina, que agencia e explica o Acaso, ensejando o assalto e, em sequência, um final feliz.

O Fait Divers, no caso de Coincidência, revelou o seu caráter imanente. Saiu de um delito, para o resgate da pacificação social. É sintagmático, em sua essência. Reivindica apenas o envolvimento emocional com o fato, em sua interpelação sensacionalista.

Barthes (2003, p. 178-179) refere que "toda a Ideologia, para mim, só é linguagem: é um discurso, um tipo de discurso". Ele a nomeia, como Ideosfera, explicando: "[...] É um sistema discursivo forte, não idioletal (que um grande número de homens pode imitar, falar, sem saber [...]" (Barthes, 2003, p.178-179).

A Ideosfera, na concepção barthesiana (Barthes, 2003), apresenta quatro subcategorias básicas. São a Doxosfera - a esfera da Doxa -, a Piteosfera - a esfera da fé -, o Socioleto - o grau zero da escrita, o apego à Neutralidade - e a Logosfera - a linguagem naturalizada.

A Ideosfera da matéria, publicada pelo Diarinho, trouxe algumas evidências. Particularizou a Doxosfera, através do Fait Divers de Coincidência e da coloquialidade de gírias e da lógica do Estereótipo. Também, notabilizou a Piteosfera, com a fé em Tiquê, como Deus-ex-machina. Ainda, neutralizou o sentido histórico, assumindo o sentido a-histórico - o Socioleto. Por fim, evidenciou a Logosfera, que esvaziou a linguagem de seu sentido histórico e cultural. Naturalizou-a, como uma produção metafísica.

Assim sendo, a matéria analisada ensejou algumas evidências. Revelou o Diarinho, em sua autenticidade e singularidade sensacionalista. A sua Ideosfera, através da Doxosfera, da Piteosfera, do Socioleto e da Logosfera, informou a sua incapacidade de ser independente, em termos históricos. Dialoga, em sua produção de sentido, com os signos, que reproduzem o status quo.

Os Poderes do Diarinho podem ser observados nas suas diversidades e nas suas unidades. Um é o Poder da Representação de pautar o que deve ser 
pautado, de pensar o que deve ser pensado e de falar o que deve ser falado no curso e no recurso do cotidiano, através dos recursos tecnológicos.

Há, ainda, o Poder da Cultura (como forma de ser e de conhecer), que tem a hegemonia do Positivismo. Caracteriza-se pela esquizofrenização entre a razão e a emoção, entre o objeto e o sujeito e entre a certeza e a incerteza. Trabalha, de modo bipolar, nos extremos do maniqueísmo.

Cabe acrescentarmos o Poder da Ideologia (como visão de mundo, que, quando absolutizada, pode se tornar distorção). Parece se particularizar, na contemporaneidade, no Neoliberalismo, afirmando e confirmando a exacerbação do Estado Mínimo, do individualismo e do fetichismo do Mercado.

Por fim, provisoriamente, existe o Poder da Economia, onde as Mídias estão comprometidas com a expansão do consumo, através da Publicidade. Desenvolvem os sentidos histéricos da eternização dos desejos insatisfeitos, transferidos, para a concretude consumista.

Complexamente, podemos evidenciar que existem Sensacionalismos no Sensacionalismo. São discursos, que exploram os conflitos dramáticos e trágicos, prioritariamente, através da forma e, secundariamente, via conteúdo. Isso pode ocorrer nos processos de seleção e de organização dos discursos, de diferentes gêneros da Mídia impressa e eletrônica.

Portanto, o Sensacionalismo do Diarinho se materializou na Doxosfera, na Piteosfera, no Socioleto e na Logosfera. Esteve associado aos Poderes da Representação, da Cultura, da Economia e da Ideologia. Isso singularizou a sua produção de sentido.

\section{Referências}

ALTHUSSER, Louis. O Futuro dura muito tempo. São Paulo: Companhia das Letras, 1992.

BARTHES, Roland. Aula. 3a. ed. São Paulo: Cultrix, 1996.

Escritores, Intelectuais, Professores e outros ensaios. Lisboa: Presença, s.d.

A Aventura Semiológica. Lisboa: Edições 70, 1987.

O Rumor da Língua. Lisboa: Edições 70, 1988.

Elementos de Semiologia. 10a ed. Rio de Janeiro: Cultrix, 1997.

Ensaios Críticos. Lisboa: Edições 70, 1971.

O Neutro. São Paulo: Martins Fontes, 2003. 
Sistema da Moda. Lisboa: Edições 70, 1979.

. Mitologias. 4ª ed. Rio de Janeiro: Bertrand Brasil, 1993.

BAUDRILLARD, Jean. A Sociedade de Consumo. Rio de Janeiro: Elfos, 1995.

GLÜCK, Renê (Org.). Itajaí turística e cultural. Itajaí: Revimar, 2000.

MORIN, Edgar. Cultura de Massas no século XX: o espírito do tempo - 1, Neurose. Rio de Janeiro: Forense Universitária, 1984.

LACAN, Jacques. O Seminário: os quatro conceitos fundamentais da psicanálise, livro

11. Rio de Janeiro: Jorge Zahar, 1996.

DIARINHO, Expediente. Itajaí, ano XXVII, n. 6826, 25 de jan. de 2005, p. 2.

. On-line. Disponível em: <wwww.diarinho.br> . Acesso em: 30 out 2014.

SOMMER, Vera Lucia. Diário do Litoral: o caminho da notícia num jornal sensacionalista do Vale do Itajaí - um estudo de caso. 2003. Dissertação (Mestrado em Comunicação Social) - Faculdade de Comunicação Social, PUCRS, 2003.

Recebido em: 16 dezembro 2014

Aceito em: 26 fevereiro 2015

Endereço do autor:

Roberto José Ramos <rr@pucrs.br>

Programa de Pós-Graduação da Pontifícia Universidade

Católica do Rio Grande do Sul - PPGCOM/PUCRS

Av. Ipiranga, 6681, Prédio 7, Sala 319| Bairro Partenon

CEP: 90619-900 | Porto Alegre, RS, Brasil

Tel/Fax: 55513320.3658 